\title{
Ditongos crescentes: um conceito fonológico ou fonético?
}

\author{
Rising diphthongs: a phonological or a phonetic concept? \\ Lurdes Ferreira \\ Universidade do Porto - Porto - Portugal
}

\begin{abstract}
$\diamond$
Resumo: Este estudo tem como objetivo verificar a intuição de estudantes do $7^{\circ}$ ano de escolaridade relativamente ao estatuto da sequência de vogais em posição pré-tónica, tónica e pós-tónica, em Português Europeu. Os resultados demonstraram que os estudantes tendem a não considerar a sequência de Glide e Vogal como ditongo em nenhuma das situações testadas. Esta tendência parece vir ao encontro a uma grande parte dos estudos, que apontam para a inexistência de glides a nível fonológico, embora possam ocorrer a nível fonético.
\end{abstract}

Palavras-chave: Ditongos; Acento; Glide; Vogal

\begin{abstract}
The study aim is to verify the intuition of students from 7 th grade on the status of the sequence of vowels in the pretonic, tonic and post-tonic position in European Portuguese. The results showed that students tend not to consider the sequence of glide and vowel as diphthong in any of the situations tested. This trend seems to come to meet a large part of the studies, which point to the lack of glides the phonological level, although they may occur at the phonetic level.
\end{abstract}

Keywords: Diphthongs; Accent; Glide; Vowels

\section{Introdução}

Antes de nos centrarmos no tema deste estudo - o ditongo -, torna-se essencial referir brevemente o conceito de sílaba, uma vez que este será essencial para determinar o estatuto de uma sequência de vogais em posição pré-tónica, tónica e pós-tónica.

Para Mateus e Andrade (2000, p. 38), a silaba é uma construção percetiva, gerada na mente do ouvinte. Os falantes reconhecem intuitivamente a existência de sílabas na sua língua-mãe e essa intuição torna-se evidente em alguns lapsos de língua.

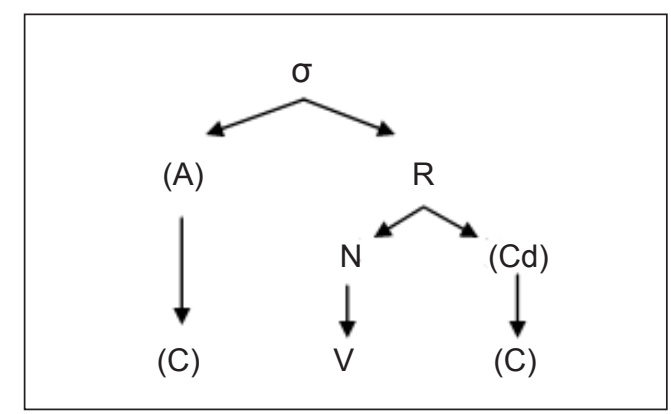

Figura 1 - Estrutura tradicional de uma sílaba
Tradicionalmente, considera-se que uma sílaba é constituída por ataque (A) e rima (R), sendo que esta domina um núcleo $(\mathrm{N})$, o qual pode ser seguido por uma coda $(\mathrm{Cd})$. O núcleo, na língua portuguesa, uma vez que não há consoantes silábicas, é sempre uma vogal (V), que pode ainda ser seguida de uma consoante $(\mathrm{C})$ ou de uma glide (G) (ANDRADE, 2002, p. 184).

Esta estrutura silábica não permite descrever uma sílaba que inclua um ditongo, entendido como um grupo de dois fonemas vocálicos pronunciados na mesma sílaba sonora (MATTOSO CÂMARA JR., 1997, p. 124). Essa sequência de fonemas é constituída por uma vogal silábica, tónica ou átona, que é a base, e por uma vogal auxiliar assilábica - glide ou semivogal -, átona, que precede a base, na parte crescente da sílaba, formando um ditongo crescente, ou que se segue à base, na parte decrescente da sílaba e forma ditongo decrescente (idem, p. 125).

Neste artigo, o nosso objeto de estudo circunscrevese a um dos tipos de ditongo nomeados - o ditongo crescente. Assim, procuraremos, em primeiro lugar, apresentar algumas características de um ditongo, para seguidamente analisarmos as estruturas propostas para representar esse tipo de ditongo. 
$\mathrm{O}$ artigo encontra-se estruturado da seguinte forma. Na secção 2 fazemos uma breve revisão da noção de ditongo, centrando-nos no ditongo crescente - o nosso objeto de estudo - e na estrutura silábica que este implica. A secção 3 refere-se ao estudo experimental e subdividese em duas: a 3.1., na qual apresentamos os procedimentos metodológicos que orientaram a investigação, e a 3.2., na qual se reproduzem os resultados da investigação, que serão discutidos na secção 4. Finaliza-se o artigo na secção 5, sintetizando o essencial dos resultados obtidos e levantando-se algumas questões para investigação futura.

\section{Problema e Hipótese}

Os sons, que dão materialidade física às categorias linguísticas, dividem-se, no nível fonológico, em duas grandes classes: vogais e consoantes. No nível fonético encontram-se, além dessas classes, duas glides ou semivogais - [j] e [w]. A glide é uma unidade fonética, com características idênticas a uma vogal, mas distinguindo-se desta por apresentar uma pronúncia mais breve, não ser acentuável e não constituir núcleo de sílaba (MATEUS, 2002, p. 172; MATEUS, 2003, p. 993).

Quando glide e vogal formam um ditongo, ambas passam a fazer parte do núcleo, embora, no registo silabado, as glides possam ser pronunciadas como vogais, dando origem à formação de duas sílabas com núcleo silábico próprio (MATEUS, 1996, p. 177).

Os encontros vocálicos que formam um ditongo encontram-se listados em diferentes gramáticas. Selecionamos duas - a Nova Gramática do Português Contemporâneo (CUNHA e CINTRA, 1997, p. 48-51), e a Gramática da Língua Portuguesa (MATEUS, 2003, p. 993-996; 1044-1045) - e apresentamos os ditongos enunciados nessas gramáticas na Tab. 1 .

Tabela 1 - Listagem de ditongos

\begin{tabular}{|c|c|c|c|}
\hline \multicolumn{4}{|c|}{ Ditongos Orais } \\
\hline \multicolumn{2}{|c|}{$\begin{array}{l}\text { Nova Gramática do } \\
\text { Português Contemporâneo }\end{array}$} & \multicolumn{2}{|c|}{$\begin{array}{l}\text { Gramática da } \\
\text { Língua Portuguesa }\end{array}$} \\
\hline Decrescentes & Crescentes & Decrescentes & Crescentes \\
\hline $\begin{array}{l}\text { [aj], [ej], [aw], } \\
\text { [ej], [ew], [عw], } \\
\text { [iw], [oj], [0j], } \\
\text { [uj] }\end{array}$ & $\begin{array}{l}\text { Ditongos com } \\
\text { [w] precedida } \\
\text { de }[\mathrm{k}] \text { ou de } \\
\text { [g] }\end{array}$ & $\begin{array}{l}\text { [aj], [ej], [aw], } \\
\text { [ej], [ew], [عw], } \\
\text { [iw], [oj], [गj], } \\
\text { [uj] }\end{array}$ & $\begin{array}{l}\text { Apenas existem } \\
\text { a nível fonético }\end{array}$ \\
\hline
\end{tabular}

A partir da Tab. 1 verificamos que as duas gramáticas indicam os mesmos ditongos decrescentes, mas apresentam uma atitude diferente perante os ditongos crescentes. Essa diferença parece resultar do facto de os dois tipos de ditongos - decrescentes e crescentes originarem estruturas silábicas diferentes.
Mateus e Andrade (2002, p. 285) propõem para um ditongo decrescente, no qual vogal e glide pertencem ao núcleo, uma estrutura silábica semelhante à ilustrada pela Fig. 2.

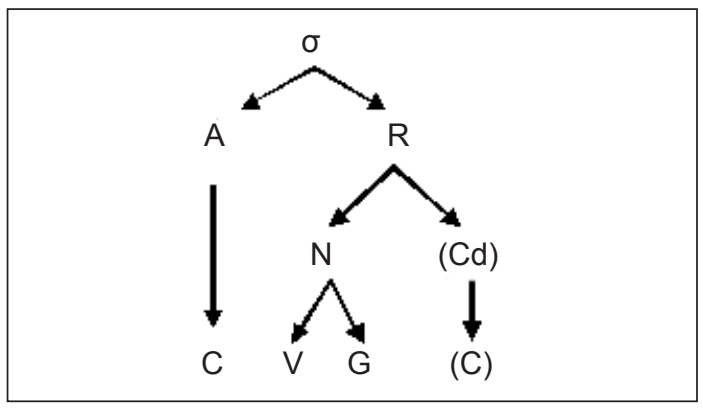

Figura 2 - Estrutura de uma sílaba com ditongo decrescente

Um ditongo decrescente pode ocorrer em posição tónica, pré-tónica ou pós-tónica. $\mathrm{Na}$ maior parte destes ditongos, a glide é fonologicamente uma vogal subespecificada e os dois constituintes do ditongo fazem parte do núcleo, facto que se comprova por as duas vogais serem afetadas por processos como a nasalidade (MATEUS e ANDRADE, 2002, p. 285).

Esta estrutura não descreve, no entanto, um ditongo crescente. Vários autores defendem que não existem ditongos crescentes no nível fonológico, uma vez que os falantes atribuem o estatuto de vogal ao segmento que a precede (MATA DA SILVA, 1987, p. 388; BISOL, 1999, p. 725; ANDRADE e VIANA, 1994, p. 31; MATEUS e ANDRADE, 2000, p. 49; FREITAS, 2001, p. 215; OLIVEIRA, MOUTINHO e TEIXEIRA, 2005, p. 2933). Além disso, o estatuto desse segmento - uma vogal alta não acentuada, que precede outra vogal - pode ser confirmado, dado que essa vogal pode ser acentuada em palavras que apresentam uma relação morfológica e fonológica, como a que ocorre entre pio [piw] e piar [piár] ou suo [súw] e suar [suár]. No entanto, as mesmas vogais, no registo coloquial, quando não são acentuadas e seguidas por outra vogal, apresentam uma duração e uma intensidade mais reduzida, pelo que podem ser percecionadas pelos falantes como pertencendo ambas à mesma sílaba: [pjár] e [swác] (BISOL, 1989, p. 215; OLIVEIRA, 2009, p. 72).

Assim, o acento parece assumir um papel essencial (ANDRADE, 1998, p. 91-92): há uma maior tendência para a perceção da sequência referida como hiato em sílabas pretónicas, como em voador, ou sempre que o acento recai na vogal imediatamente a seguir à vogal que pode sofrer semivocalização, como em coelho. Em oposição, quando a sequência ocorre em posição póstónica, como canário, a tendência é para a sua perceção como ditongo (CABELEIRA e CORREIA, 2003, p. 357). 
A mesma leitura é transmitida por estudos fonéticos, segundo os quais o conjunto de duas vogais átonas em posição de final de palavra em português é um ditongo (DRENSKA, 1986, p. 64; MATA DA SILVA, 1987, p. 399). Essa constatação não impede, no entanto, que esse segmento seja considerado uma vogal, no nível fonológico, uma vez que, quando ocorre antes de uma vogal nasal, não é afetada por esse processo (ANDRADE e VIANA, 1994, p. 36; MATEUS e ANDRADE, 2002, p. 287; OLIVEIRA, MOUTINHO e TEIXEIRA, 2005, p. 2933; OLIVEIRA, 2009, p. 72). Estas são as palavras designadas como falsas esdrúxulas, designação que "decorre da assimetria entre a oralidade e a escrita: nestas palavras, há marcação gráfica do acento na vogal que, na produção da palavra, é a penúltima e que, na ortografia, é a antepenúltima" (FREITAS, RODRIGUES, COSTA e CASTELO, 2012, p. 111), como se ilustra na Tab. 2.

Tabela 2 - Falsas esdrúxulas

\begin{tabular}{lccc}
\hline \multicolumn{3}{c}{ Modos } & \multicolumn{3}{c}{ Divisão silábica } \\
\hline Escrita & vi & tó & ria \\
Oralidade & {$[\mathrm{vi}]$} & {$[\mathrm{tó}]$} & {$[\mathrm{rjœ]}$} \\
\hline
\end{tabular}

(CF. FREITAS, RODRIGUES, COSTA e CASTELO, 2012, p. 111)

Além da acentuação, a velocidade de articulação de palavras como piar ou suar pode alterar o número de sílabas das mesmas: num registo rápido, pode ocorrer a realização de um ditongo crescente, apresentando a palavra uma única sílaba; no entanto, num registo pausado, os dois elementos podem ser interpretados como a realização de duas vogais, pertencentes a sílabas diferentes (MOUTINHO, 2000, p. 541; FREITAS e SANTOS, 2001, p. 43; FREITAS, RODRIGUES, COSTA e CASTELO, 2012, p. 108-9). Assim, as vogais [u, i], em posição átona, apresentam duas realizações - uma como vogais e outra como glides - dependendo da velocidade da fala, como se apresenta na Tab. 3 .

Tabela 3 - Semivocalização de [i] e de [u] em hiato

\begin{tabular}{lcc}
\hline & Velocidade de fala lenta & Velocidade de fala rápida \\
\hline teatro & [tiátru] & [tjátru] \\
viola & [vióle] & [vjóle] \\
pianista & [pieníste] & [pjeníste] \\
miúdo & [miúdu] & [mjúdu] \\
\hline
\end{tabular}

(CF. FREITAS, RODRIGUES, COSTA e CASTELO, 2012, p. 108)

\footnotetext{
1 Assim, num registo rápido, é possível admitir os seguintes ditongos

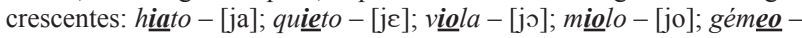
[ju]; moe $d a-[\mathrm{w} \varepsilon] ;$ moer - [we] (MOUTINHO, 2000, p. 54).
}

Este facto é ainda sublinhado pela possibilidade de separar, na escrita, os dois grafemas que correspondem ao ditongo crescente. Numa situação de translineação, não é permitido separar os grafemas que correspondem a um ditongo decrescente, uma vez que ambos pertencem à mesma sílaba (pau-ta / *pa-uta). No caso dos ditongos crescentes, esta partição é possível (pia-no / pi-ano), o que indicia a existência de uma fronteira intersilábica entre as duas vogais (OLIVEIRA, 2009, p. 72-73).

Por oposição, quando as vogais [i] e [u] são acentuados, o processo de semivocalização não ocorre, como se ilustra na Tab. 4.

Tabela 4 - Realização das vogais [i] e [u] quando acentuadas

\begin{tabular}{cc}
\hline [i, u] tónicos & [i, u] átonos \\
\hline dia [díœ] & diabo [djábu] / [diábu] \\
lua [lúœ] & luar [lwár] / [luár] \\
\hline
\end{tabular}

(CF. FREITAS, RODRIGUES, COSTA e CASTELO, 2012, p. 110)

Assim, enquanto os ditongos decrescentes são "ditongos verdadeiros", dado apresentarem realizações mais estáveis, os ditongos crescentes não têm estabilidade, podendo quase sempre ser pronunciados em hiato (ANDRADE e VIANA, 1994, p. 31), dependendo a opção de dois fatores: a acentuação e a velocidade do registo.

Os ditongos crescentes seriam, assim, derivações pós-lexicais, formados por ressilabificação (BISOL, 1999, p. 724). Essas ramificações silábicas são sempre binárias a nível lexical, mas estariam livres desta condição no nível pós-lexical. Esta é a explicação para que um falante, a quem se solicite a silabação de palavras como fiança, aliado ou história, faça fi.an.ça, a.li.a.do, his.tó.ri.a, dando à vogal alta o estatuto de núcleo silábico, mas tendencialmente não o faça com palavras do tipo: teimoso, perau ou leitura (idem, p. 725). Assim, como em português só uma vogal pode funcionar como núcleo silábico, as sequências de duas vogais (VV) seriam sempre dissilábicas no nível lexical.

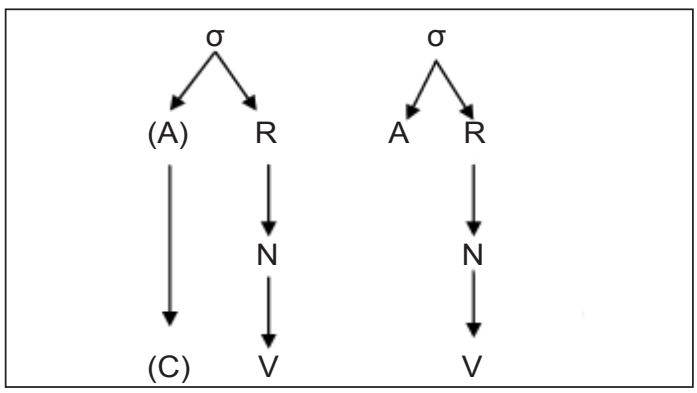

Figura 3 - Estrutura de uma sílaba com ditongo crescente 
De acordo com a Fig. 3, num ditongo crescente, a segunda vogal de uma sequência constitui o núcleo de uma sílaba de ataque vazio. Concluiu-se a partir daqui que as glides são vogais na estrutura subjacente. No entanto, no discurso coloquial, essa vogal subjacente pode ser produzida como glide (MATEUS e ANDRADE, 2002, p. 287).

Rua (2005, p. 89), num estudo experimental sobre ditongos orais no português europeu, verifica que apesar de existirem diferenças na duração das vogais nas duas sequências (crescente ou decrescente), essas diferenças são insuficientes para distinguirem os dois tipos de ditongos, sublinhando que os resultados obtidos não permitem excluir definitivamente a existência de ditongos crescentes, pela influência entre a parte vocálica e a glide.

Apesar do que referimos anteriormente, vários autores (BISOL, 1989, p. 215; VIGÁRIO e FALÉ, 1994, p. 467; MATTOSO CÂMARA JR., 1997, p. 125; FREITAS, 2001, p. 220; RUA, 2005; MATTOSO CÂMARA JR., 2008, p. 56-57; CARVALHO, 2012, p. 19) defendem que existe um caso restrito de ditongo crescente: as sequências vocálicas onde, obrigatoriamente, a semivogal arredondada [w] se apresenta precedida de [k] (grafado q) e [g]. Neste contexto, a sequência $[\mathrm{kw}]$ e $[\mathrm{gw}]$ é processada como $/ \mathrm{k}^{\mathrm{w}} / \mathrm{e} / \mathrm{g}^{\mathrm{w}} /$, o que implica que o seu estatuto segmental seja o de consoantes velares labializadas e o seu estatuto silábico de ataques não ramificados (FREITAS, 2001, p. 224). Assim, em palavras como "quarto" ou "água", a alternância fonética GV/VV não se verificaria, sendo obrigatória a produção da semivogal.

No processo de ensino aprendizagem, a criança contacta com a noção de ditongo e absorve a noção didática de que um ditongo seria "um grupo constituído por vogal + semivogal ou semivogal + vogal pronunciadas numa mesma emissão de voz. Só o i e o u são semivogais" (PINTO, LOPES e NASCIMENTO, 2006, p. 40) ${ }^{2}$. No entanto, como já referimos neste trabalho, a sequência semivogal + vogal é considerada, tendencialmente, uma sequência de duas vogais, embora possa ser percecionada, em alguns casos e dependendo da acentuação da palavra, como ditongo.

Neste artigo, procuraremos demonstrar que a identificação de uma sequência semivogal + vogal como ditongo depende da posição do acento, embora a tendência seja para a sua percepção como uma sequência de vogais.

\section{Estudo experimental}

\subsection{Procedimentos metodológicos}

Os dados utilizados neste estudo foram recolhidos em junho de 2009.

\footnotetext{
2 A seleção desta Gramática justifica-se por ser a adotada no Estabelecimento de Ensino onde foi realizado o estudo.
}

Os sujeitos escolhidos - todos apresentando o português como língua materna - pertencem à mesma faixa etária, com idades compreendidas entre doze e quinze anos, que frequentavam o sétimo ano de escolaridade no ano letivo de 2008/09. A diferença de idade tem duas explicações: a entrada mais tardia no sistema escolar e a retenção no percurso escolar. Todos sujeitos selecionados frequentam o mesmo estabelecimento de ensino, situado em Penafiel, e a sua distribuição pelo número de anos de escolaridade frequentados é apresentada na Tab. 5.

Tabela 5 - Distribuição da população do estudo

\begin{tabular}{lccc}
\hline Escolaridade & 7 & 8 & 9 \\
\hline Alunos & 63 & 29 & 17 \\
\hline
\end{tabular}

Aos sujeitos foi apresentada uma lista de vocábulos variados, com estrutura silábica diferente. Foi dado um exemplo de divisão silábica de uma palavra, com uma estrutura silábica CVCV, e o aplicador do teste fez um esclarecimento prévio da tarefa pedida. Os alunos procederam à divisão silábica das palavras, anotando a resposta na folha.

Os dados foram tratados numa folha de cálculo em formato Excel, tendo sido apenas consideradas as segmentações que considerassem a sequência de vogais como ditongo ou como hiato.

As palavras-alvo deste estudo foram inseridas numa lista, onde constavam palavras que não apresentavam as sequências pretendidas, de modo a não condicionar os informantes (Anexo 1).

O conjunto de palavras que constituem o corpus subdivide-se em três grupos, de acordo com a posição do acento, conforme se apresenta na Tab. 6 .

Tabela 6 - Dados em estudo nos diferentes grupos

\begin{tabular}{cll}
\hline Grupo & \multicolumn{1}{c}{ Descrição } & \multicolumn{1}{c}{ Corpus } \\
\hline Grupo A & $\begin{array}{l}\text { semivogal + vogal, em } \\
\text { situação pós-tónica } \\
\text { vogal + vogal, em situação } \\
\text { pré-tónica }\end{array}$ & $\begin{array}{l}\text { água; águia; ardósia; } \\
\text { canário; pátio; petróleo } \\
\text { realeza; voador }\end{array}$ \\
Grupo C & $\begin{array}{l}\text { semivogal + vogal, em } \\
\text { situação tónica }\end{array}$ & $\begin{array}{l}\text { miúdo; luar; real; coelho; } \\
\text { quieta; piano; pior; teatro; } \\
\text { viagem; viola }\end{array}$ \\
\hline
\end{tabular}

Em todas as palavras dos três grupos há uma vogal alta que, de acordo com Cabeleiro e Correia (2003, p. 355), pode ser alvo de semivocalização.

\subsection{Apresentação dos resultados}

O nosso objetivo era verificar se os sujeitos identificam a sequência de duas vogais como ditongos 
crescentes e procurar estabelecer os contextos em que tal se verifica. Como já referimos, o corpus em estudo foi subdividido em três grupos, de acordo com a posição do acento e a apresentação dos resultados respeita essa divisão. Os grupos A e B foram ainda subdivididos, de acordo com o número de sílabas das palavras.

Num primeiro momento serão apresentados os valores absolutos e as percentagens para cada um dos itens que compõem os diferentes grupos. Em seguida, será realizada uma análise comparativa das médias dos desempenhos globais por grupo.

\subsubsection{Análise do desempenho dos grupos}

Na Tab. 7 são apresentados os valores absolutos e as respectivas percentagens para cada item do Grupo A.

Uma primeira leitura dos resultados permite destacar uma tendência para a perceção da sequência de vogais, em posição pós-tónica, como hiato. Essa tendência é mais acentuada na palavra "águia" do que nas restantes. Em oposição, a segmentação da palavra "petróleo" apresenta valores muito próximos entre as duas opções - ditongo ou hiato.
Parece-nos igualmente importante sublinhar que os valores relativos à perceção da sequência de vogais como ditongo são mais elevados quando o número de sílabas é maior (Grupo A1), como podemos constatar a partir dos valores globais calculados para cada subgrupo.

A Tab. 8 apresenta os resultados referentes a cada item do Grupo II, no qual se regista a perceção dos alunos da sequência de vogais em posição tónica.

Mais uma vez, os resultados indiciam, também para este grupo, a tendência para a perceção da sequência de vogais, em posição tónica, como hiato. Essa tendência é, neste grupo, mais clara, uma vez que a maioria dos itens apresenta valores acima de $80 \%$.

Também neste grupo se observa que há maior tendência para a perceção da sequência em estudo como ditongo quando o número de sílabas da palavra é maior, ou seja, os valores registados para a perceção da sequência como ditongo são mais elevados no grupo B1 $(16,8 \%)$ do que no B2 $(4.9 \%)$.

Por fim, a Tab. 9 apresenta os resultados referentes a cada item do Grupo III, no qual se regista a perceção dos alunos da sequência de vogais em posição pré-tónica.

Tabela 7 - Valores absolutos e respetiva percentagem para o Grupo A

\begin{tabular}{|c|c|c|c|c|c|c|c|c|c|}
\hline \multicolumn{10}{|c|}{ Grupo A - Sequência de vogais em posição pós-tónica } \\
\hline \multirow{2}{*}{\multicolumn{2}{|c|}{ Palavra-teste }} & \multicolumn{8}{|c|}{ Segmentação } \\
\hline & & Ditongo & $\mathrm{N}=109$ & $\%$ & $\%$ & Hiato & $\mathrm{N}=109 \%$ & $\%$ & $\%$ \\
\hline \multirow{3}{*}{ A1 } & ardósia & sia & 42 & 38.5 & & si-a & 67 & 61.5 & \\
\hline & canário & rio & 43 & 39.4 & 41.9 & ri-o & 66 & 60.6 & 58.1 \\
\hline & petróleo & leo & 52 & 47.7 & & le-o & 57 & 52.3 & \\
\hline \multirow{3}{*}{ A2 } & água & gua & 36 & 33.0 & & gu-a & 72 & 66.1 & \\
\hline & águia & guia & 14 & 12.8 & 25.4 & gui-a & 93 & 86.2 & 73.7 \\
\hline & pátio & tio & 33 & 30.3 & & ti-o & 75 & 68.8 & \\
\hline
\end{tabular}

Tabela 8 - Valores absolutos e respetiva percentagem para o Grupo B

\begin{tabular}{|c|c|c|c|c|c|c|c|c|c|}
\hline \multicolumn{10}{|c|}{ Grupo B - Sequência de vogais em posição tónica } \\
\hline \multirow{2}{*}{\multicolumn{2}{|c|}{ Palavra-teste }} & \multicolumn{8}{|c|}{ Segmentação } \\
\hline & & Ditongo & $\mathrm{N}=109$ & $\%$ & $\%$ & Hiato & $\mathrm{N}=109 \%$ & $\%$ & $\%$ \\
\hline \multirow{7}{*}{ B1 } & coelho & coe & 19 & 17.4 & & coe & 90 & 82.6 & \\
\hline & miúdo & miú & 17 & 15.6 & & mi-ú & 92 & 84.4 & \\
\hline & piano & pia & 12 & 11.1 & & pi-a & 97 & 88.9 & \\
\hline & quieta & quie & 9 & 8.3 & 16.8 & qui-e & 100 & 91.7 & 83.1 \\
\hline & teatro* & tea & 31 & 28.4 & & te-a & 77 & 70.6 & \\
\hline & viagem & via & 22 & 20.2 & & vi-a & 87 & 79.8 & \\
\hline & viola & vio & 18 & 16.5 & & vi-o & 91 & 83.5 & \\
\hline \multirow{3}{*}{ B2 } & luar & luar & 4 & 3.7 & & lu-ar & 105 & 96.3 & \\
\hline & pior & pior & 5 & 4.6 & 4.9 & pi-or & 104 & 95.4 & 95.1 \\
\hline & real & real & 7 & 6.4 & & real & 102 & 93.6 & \\
\hline
\end{tabular}

* Um dos alunos não efetuou uma divisão silábica, pelo que a sua resposta não foi considerada. 
Tabela 9 - Valores absolutos e respetiva percentagem para o Grupo III

\begin{tabular}{|c|c|c|c|c|c|c|}
\hline \multicolumn{7}{|c|}{ Grupo C - Sequência de vogais em posição pré-tónica } \\
\hline \multirow{2}{*}{ Palavra-teste } & \multicolumn{6}{|c|}{ Segmentação } \\
\hline & Ditongo & $N=109$ & $\%$ & Hiato & $\mathrm{N}=109$ & $\%$ \\
\hline voador & voa & 20 & 18.4 & vo-a & 89 & 81.7 \\
\hline realeza & rea & 28 & 25.7 & rea & 81 & 74.3 \\
\hline
\end{tabular}

Em relação ao Grupo III, os resultados mostram igualmente a tendência clara para a perceção da sequência de vogais, em posição pré-tónica, como hiato.

Verificamos a mesma relação entre o número de sílabas e a perceção da sequência de vogais em estudo.

\subsubsection{Comparação entre o desempenho dos grupos}

Em seguida, calculou-se a média do desempenho em cada grupo, conforme se apresenta na Tab. 10.

Tabela 10 - Médias por Grupo

\begin{tabular}{ccc}
\hline \multirow{2}{*}{ Grupo } & \multicolumn{2}{c}{ Segmentação } \\
\cline { 2 - 3 } & Ditongo & Hiato \\
\cline { 2 - 3 } & $\%$ & $\%$ \\
\hline A & 34 & 66 \\
B & 14 & 86 \\
C & 22 & 78 \\
\hline
\end{tabular}

Os resultados permitem constatar, mais uma vez, uma clara tendência para a perceção de uma sequência de vogais como hiato, em todos os contextos em análise. Essa tendência é mais acentuada quando o ditongo se encontra em sílabas tónicas e pré-tónicas.

\section{Discussão dos resultados}

Perante a necessidade de segmentação de palavras com estruturas como as apresentadas nos três grupos do estudo, as respostas dos sujeitos revelam uma grande alternância entre vogal e glide. Essa alternância foi constatada em trabalhos anteriores, nos quais se assinala a velocidade de produção (FREITAS e SANTOS, 2001, p. 452) e a acentuação como fatores que influenciam a segmentação referida, indicando que existem duas divisões silábicas para uma mesma palavra (CARVALHO, 2012, p. 16).

Os resultados parecem confirmar a literatura consultada e mostram que os ditongos crescentes são instáveis, podem ser pronunciados quase sempre em hiato (ANDRADE e VIANA, 1994, p. 31). Se considerarmos que as glides não apresentam um estatuto fonológico, seria então previsível que os sujeitos as considerassem como vogais e as silabificassem. De acordo com Mateus (2003, p. 993), as sílabas em português apresentam sempre como núcleo uma vogal, consequentemente nem as consoantes nem as glides poderão ser núcleo de sílaba. A divisão que um falante faz de uma palavra implica assim a identificação de sílabas, em cujo núcleo exista sempre uma vogal. Seria pois de esperar que os sujeitos deste estudo segmentassem as palavras em função das vogais nelas presentes. A Tab. 7 mostra uma tendência generalizada para a segmentação de uma sequência de vogais, ou seja, existe uma fronteira silábica entre os dois elementos das sequências em estudo (OLIVEIRA, MOUTINHO e TEIXEIRA, 2005, p. 2933; OLIVEIRA, 2009 , p. 72-3). A sequência GV está em variação livre com a vogal alta correspondente. Assim, a segmentação das vogais resulta de uma ressilabificação pós-lexical. Desta forma, admitimos que os ditongos crescentes são estruturas marcadas, não fazem parte do inventário fonológico do português e surgem da fusão de duas sílabas diferentes (BISOL, 1999, p. 111; BISOL, 1989, p. 215; CABELEIRA e CORREIA, 2003, p. 357) ${ }^{3}$.

Essa influência parece mais permeável nos casos em que a sequência GV surge em posição pós-tónica. Uma comparação dos resultados mostra que há uma maior tendência dos sujeitos deste estudo para identificarem as sequências nomeadas como ditongos do que aquelas que se encontram em posição tónica ou pré-tónica. Estes resultados vêm de encontro a estudos anteriores com alunos de um nível de escolaridade semelhante. Num estudo com alunos de anos de escolaridade diferentes (um grupo de $5^{\circ}$ ano e outro de $8^{\circ}$ ), verificou-se que, no nível escolarizado mais avançado, os alunos revelaram dois comportamentos perante a estrutura GV: "ou preferem o hiato em sílabas pré-tónicas e sempre que o acento recai na vogal imediatamente a seguir à vogal que pode sofrer semivocalização, ou preferem o ditongo crescente, no caso das 'falsas esdrúxulas', em posição pós-tónica" (CABELEIRA e CORREIA, 2003, p. 357). Sublinhe-se, no entanto, que os sujeitos do nosso estudo, em oposição aos do estudo nomeado, demonstram ainda nesses casos preferência pelo hiato.

A observação cuidada dos dados motivou a divisão dos grupos A e B em A1 e A2 e em B1 e B2, respetivamente. Esta divisão mostra que a perceção da sequência em estudo pode depender ainda do número de sílabas da palavra. Assim, a perceção da sequência como hiato é mais elevada quando o número de sílabas é menor.

\footnotetext{
Na listagem de ditongos apresentada na Tab. 1 verifica-se que esta ideia é generalizada.
} 
Os estudos parecem unânimes na atribuição de um estatuto diferente às sequências $q u$ e $g u$, consideradas como duas consoantes por Mateus (2002, p. 261). Mattoso Câmara Jr. (1997, p. 125) apenas admite "um caso restrito de ditongo crescente, porque a prepositiva /w/ só aparece depois da consoante oclusiva velar $(/ \mathrm{k} /, / \mathrm{g} /)$, que é então grafada com a letra $q$ quando surda (ex.: qual, igual)". Assim, a glide parece surgir quer devido a um processo de ressilabificação quer à articulação secundária de certos $/ \mathrm{k} / \mathrm{s} \mathrm{e} / \mathrm{g} / \mathrm{s}$. Por outro lado, as glides fazem parte do mesmo constituinte silábico porque, quando temos uma sequência de duas vogais, estas pertencem a duas sílabas diferentes, a dois Núcleos diferentes; pelo contrário, quando temos a sequência de uma glide seguida de vogal, a vogal ocupa uma posição do esqueleto associada ao Núcleo e a glide está associado a uma posição ligada ao Ataque (ANDRADE e VIANA, 1993, p. 37).

No estudo apresentado, no contexto referido, os sujeitos mostraram tendência para considerar a existência de duas vogais, como se constata pelos resultados apresentados na Tab. 4 para a palavra água. Esta observação contradiz a bibliografia referida, mostrando que há também neste caso alternância entre hiato e ditongo. Assim, para os sujeitos do nosso estudo, ao contrário do que é defendido por diferentes autores (BISOL, 1989, p. 215; VIGÁRIO E FALÉ, 1994, p. 467; MATTOSO CÂMARA JR., 1997, p. 125; FREITAS, 2001, p. 220; CARVALHO, 2012, p. 19), este não é um caso restrito de ditongo crescente.

\section{Conclusão}

O presente estudo demonstra que há uma tendência para a população-alvo não considerar a existência fonológica da Glide. Este comportamento pode diferir de acordo com a posição do acento na palavra. Assim, há uma tendência maior para a segmentação da sequência Glide + Vogal, quando esta se encontra em posição tónica do que quando se encontra em posição pós-tónica. Os resultados deste estudo vêm, pois, ao encontro da literatura consultada, a qual apenas admite a existência de ditongos crescentes em contexto de final de palavra, embora sublinhe a sua natureza fonética (MATA DA SILVA, 1987, p. 399).

No entanto, e ao contrário do esperado, mesmo nos casos em que a existência da Glide está prevista, devido a um processo de ressilabificação, os sujeitos deste estudo tenderam para a segmentação, como se observa em relação aos resultados registados para a palavra "água".

Outro resultado inesperado e que necessita de uma investigação mais aprofundada é a relação detetada entre o número de sílabas da palavra e a tendência para a segmentação da sequência Glide + Vogal.

\section{Referências}

ANDRADE, Ernesto de. The Syllable Structure in European Portuguese. In: MATEUS, M ${ }^{\mathrm{a}}$ Helena Mira (Org.). A face exposta da língua portuguesa. Lisboa: Imprensa Nacional Casa da Moeda, 2002. p. 281-298.

ANDRADE, Ernesto de. Sobre a alternância vogal/glide em Português. In: Atas do XIII encontro nacional da Associação Portuguesa de Linguística. Lisboa: APL, 1998. Vol. I. p. 91-102.

ANDRADE, Ernesto de; VIANA, Maria do Céu. Sinérese, diérese e estrutura silábica. In: Atas do IX Encontro Nacional da APL. Lisboa: APL, 1994. p. 31-42.

BISOL, Leda. O ditongo da perspetiva da fonologia atual. In: D.E.L.T.A., v. 5, n. 2, p. 185-224, 1989.

BISOL, Leda. A sílaba e os seus constituintes. In: NEVES, Maria Helena de Moura (Org.). Gramática do português falado. Campinas: Editora Unicamp, 1999. Vol. IV: Novos estudos. p. 701-742.

CABELEIRA, Susana; CORREIA, Susana. Ditongos, tritongos e hiatos - Intuição e propostas de divisão silábica (trabalho com crianças dos 10 aos 13 anos em PE). In: Atas do XIX Encontro Nacional da Associação Portuguesa de Linguística. Lisboa: APL, 2003. p. 351-362.

CARVALHO, Joana. Sobre os ditongos do português europeu. In: eLingUp, v. 4, n. 1, p. 11-30, 2012.

CUNHA, Celso; CINTRA, Luís F. Lindley. Nova gramática do português contemporâneo. Lisboa: Edições João Sá da Costa, 1997.

DRENSKA, Margarida. Existem ditongos crescentes em posição final de palavra em português?. In: Atas do II Encontro da Associação Portuguesa de Linguística. Lisboa: APL, 1986. p. 53-74.

FREITAS, Maria João; SANTOS, Ana Lúcia. Contar (histórias de) sílabas. Descrição e implicações para o ensino do Português como Língua Materna. Lisboa: Colibri, 2001.

FREITAS, Maria João. Os ping[w]ins são diferentes dos $\mathrm{c}[\mathrm{w}]$ elhos? Questões sobre oclusivas velares, semivogais e arredondamentos na aquisição do Português Europeu. In: Atas do XVI Encontro Nacional da Associação Portuguesa de Linguística. Lisboa: APL, 2001. p. 213-225.

FREITAS, Maria João; RODRIGUES, Celeste; COSTA, Teresa; CASTELO, Adelina. Os sons que estão dentro das palavras. Descrição e implicações para o ensino do Português como Língua Materna. Lisboa: Colibri, 2012.

MATA DA SILVA, Ana Isabel, Ditongos crescentes do português: análise acústica. In: Atas do 3 encontro nacional da Associação Portuguesa de Linguística. Lisboa: APL, 1987. p. 379-400.

MATEUS, Maria Helena Mira. Onset of Portuguese Syllables and Rising Diphthongs. In: MATEUS, Maria Helena Mira. A face exposta da língua portuguesa. Lisboa: Imprensa Nacional - Casa da Moeda, 2002. p. 261-270.

MATEUS, Maria Helena Mira. A silabificação de base em português. In: MATEUS, Maria Helena Mira. A face exposta da língua portuguesa. Lisboa: Imprensa Nacional - Casa da Moeda, 2002. p. 271-279. 
MATEUS, Maria Helena Mira. Aspetos fonológicos e prosódicos da gramática do português. In: MATEUS, Maria Helena Mira et al. Gramática da língua portuguesa. 5. ed. rev. e aum. Lisboa: Caminho, 2003. p. 987-1076.

MATEUS, Maria Helena Mira. Fonologia. In: FARIA, Inês Hub et al. Introdução à linguística geral e portuguesa. Lisboa: Caminho, 1996. p. 171-199.

MATEUS, Maria Helena Mira; D’ANDRADE, Ernesto. The Phonology of Portuguese. Oxford: Oxford University Press, 2000.

MATEUS, Maria Helena Mira; D’ANDRADE, Ernesto. The syllable structure in European Portuguese. In: MATEUS, Maria Helena Mira. A face exposta da língua portuguesa. Lisboa: Imprensa Nacional - Casa da Moeda, 2002. p. 281-297.

MATTOSO CAMARA JR, Joaquim. Dicionário de linguística e gramática referente à língua portuguesa. Petrópolis: Vozes, 1997.

MATTOSO CAMARA JR., Joaquim. Para o estudo da fonêmica portuguesa. Petrópolis: Vozes, 2008.

MOUTINHO, Lurdes de Castro. Uma introdução ao estudo da fonética e fonologia do português. Lisboa: Plátano Edições Técnicas, 2000.
OLIVEIRA, Catarina Alexandra Monteiro de. Do grafema ao gesto - contributos linguísticos para um sistema de síntese de base articulatória. Tese (Doutor em Linguística) - Universidade de Aveiro, Aveiro, 2009.

OLIVEIRA, Catarina Alexandra Monteiro de; MOUTINHO, Lurdes de Castro; TEIXEIRA, António. On European Portuguese Automatic Syllabification. In: Interspeech, 9th European Conference on Speech Communication and Technology. Lisboa, 2005. p. 2933-2936.

PINTO, João Manuel de Castro; LOPES, Maria do Céu Vieira; NASCIMENTO, Zacarias. Gramática do português moderno. Lisboa: Plátano Editora, 2006.

RUA, Carla. Ditongos orais no português europeu. Dissertação (Mestre em Estudos Portugueses) - Universidade de Aveiro, Aveiro, 2009.

VIGÁRIO, Marina; FALÉ, Isabel. A sílaba no Português Fundamental: uma descrição e algumas considerações de ordem teórica. In: Atas do IX Encontro Nacional da APL. Lisboa: APL, 1994. p. 465-477.

Recebido: 12 de outubro de 2013

Aprovado: 04 de dezembro de 2013

Contato: mlurdessf@gmail.com

\section{ANEXO 1}

\section{AS SÍLABAS}

Este é um pequeno teste para um estudo universitário. Não serás avaliado por aquilo que aqui fizeres, mas as tuas respostas serão muito importantes.

Lê as palavras que se seguem e procura dividi-las em sílabas como o exemplo: casa: ca-sa

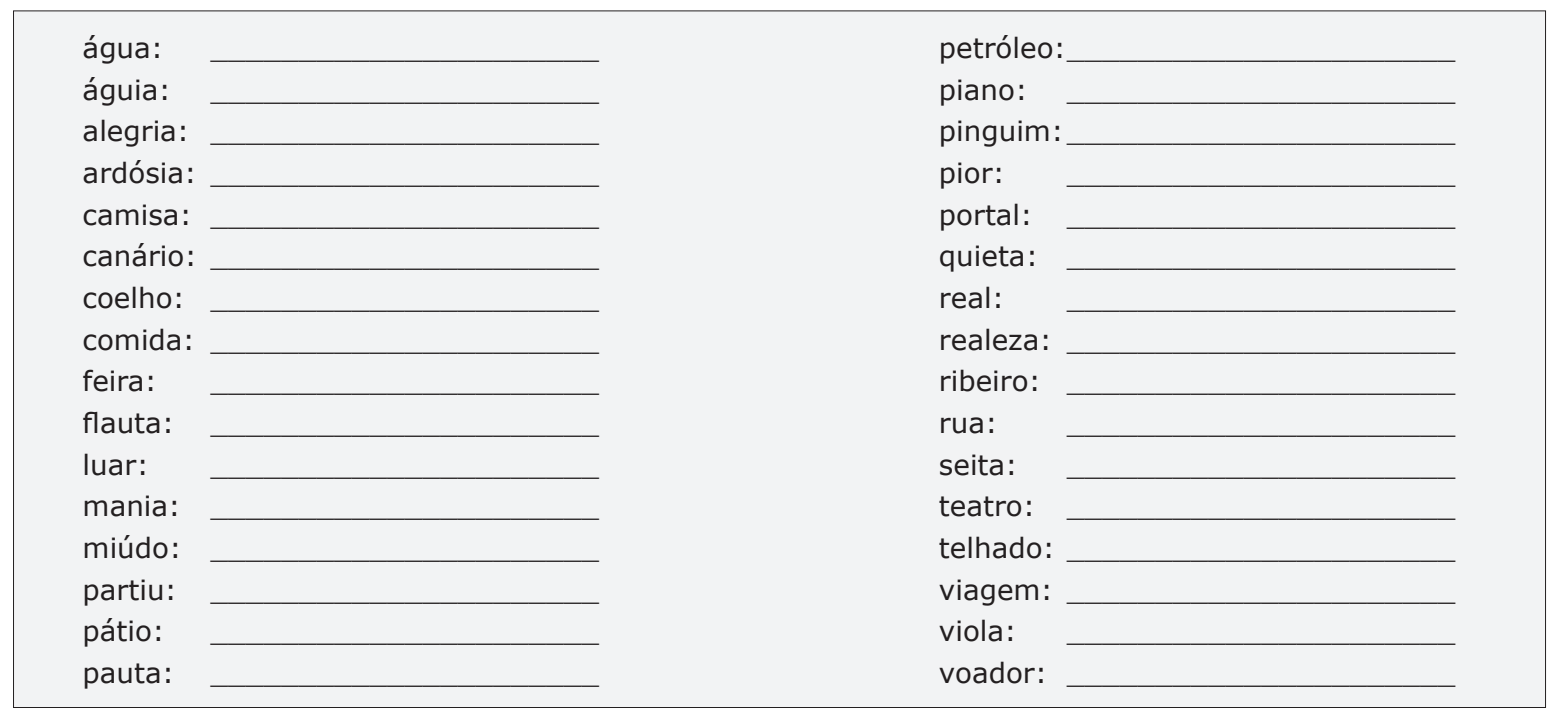

Muito Obrigada pela tua colaboração!

Idade:

Ano de Escolaridade:

No de anos de escolaridade frequentados: 